\title{
Reflections on SARS
}

SARS in context: memory, history, policy Edited by Jacalyn Duffin and Arthur Sweetman McGill-Queen's University Press; 2006 210 pp Can $\$ 29.95$

ISBN 978-0-77353-194-9

$\mathrm{L}$ essons continue to be recounted and learned in the long wake after severe acute respiratory syndrome (SARS) entered Canada 4 years ago. In February 2007 the SARS Commission to investigate the introduction and spread of SARS in Ontario, led by the Honourable Archie Campbell, released its third and final report, The Spring of Fear, a masterful account that investigates and documents the trail of the contagion and its uniquely tragic personal impact in Ontario. This third Campbell report both reduces and elevates occupational health duties and the precautionary principle (i.e., that reasonable efforts to reduce risk need not await scientific proof) to provincial and personal proportions and, some might argue, distortions. both faculty members at Queen's University, this subtle text is based on their experiences as a medical historian and policy analyst, respectively, called to duty and account in the midst of the SARS crisis. During this period, members of the media required the editors to comment on historical precedents of "plagues" and their implications. According to Duffin and Sweetman, their sage and informed comments were often received with disappointment from members of the media who were unwilling to concede that the historical lessons delivered by plagues are simple, crude, predictable and harsh. Nature is indiscriminate and humanity is conflicted by self-interest, good will, the limits of knowledge and privilege. When uncertainty prevails, time-limited dire measures may be necessary to protect the health of populations against the unknown.

This experience seems to have had a resounding impact on Duffin and Sweetman. It resulted in a post-hoc symposium, hosted by Queen's University Faculty, between academics and the

\section{Journalists were unwilling to concede that the historical lessons} delivered by plagues are simple, crude, predictable and harsh.

A few months before the release of Campbell's report, the book, SARS in Context, was published. Edited by Drs. Jacalyn Duffin and Arthur Sweetman, media, with the intention of reviewing the encounters between historians and journalists in the context of SARS. This has been captured in the book. In ap-

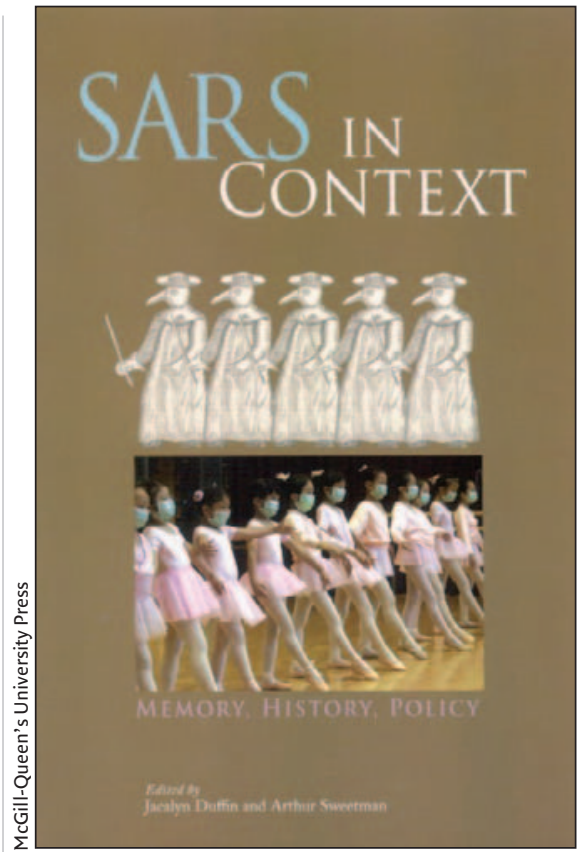

parent contrast to the title and size of the I200-page Campbell report, SARS in Context, is a slim text (2Io pages) comprising II chapters, none of which - presumably in consideration of the already overwhelmed health care professional - exceeds 25 pages.

The book begins with a brisk introduction by Duffin, followed by 3 sections. The first provides personal accounts and reflections from "medical officials" Drs. James Young and Dick Zoutman, who were called to appointment at "ground zero" in the province when SARS hit. The second section recounts analyses by various medical historians who were asked to draw comparisons between previous communityacquired epidemics (e.g., the so-called Spanish flu, cholera in Toronto, AIDS). Finally, the third section looks at the federal role and the economic impact 
of SARS - and quite effectively debunks any concerns that the latter was either significant or long lasting.

Overall, SARS in Context, provides some refreshing accounts and balanced insights; however, there are some shortfalls. The writing and editing between chapters is quite choppy. Given that reading good writing is like looking through a clear window, I must admit that in certain chapters I wanted to spray on some window cleaner. And, although I strived to refrain from wearing a personal hat on this read, I was disconcerted to see that no members of my medical specialty (community medicine) were represented in the text. Every day medical officers of health are invited to waltz between investigating sporadic cases and declaring emerging outbreaks. That we were not even listed on the dance card of the editors of SARS in Context is sobering indeed, and makes me wonder whether it signals the editors' desires or drabness of my specialty?

\section{Erica Weir}

Associate Medical Officer of Health York Region, Ont.

\section{CREATIVE CONVALESCENCE}

I enjoy convalescence. It is the part that makes the illness worth while. - George Bernard Shaw

Ignatius of Loyola, founder of the Jesuits, was converted to the religious life while recovering from a battle wound. Convalescence has been put to interesting use by many thinkers, artists and writers. Some, like Robert Louis Stevenson, became famous for it.

Tell us about recovery times yours, or your patients' - in The Left Atrium. We welcome prose submissions of up to 1000 words (pubs@cma.ca).

\section{Room for a view}

\section{That growing uneasiness buried within}

\section{Time}

They call it a Home for the Aged, whenever it's mentioned (and mentally file it away under D ... for Decrepit. And Dreary. And Death.) while they fight off their hidden reluctance to stay for that duty-bound visit. "But really, it isn't so bad, is it, dear?" with eyes tactful, averted from half-emptied bedpan.

"Young Lisa has plans

to be married this spring..." (and the subject is skirted of why Auntie Mae must be strapped to her chair, for she wanders, you see. Can't be helped. Very sad.)

and they chatter, too quickly, avoiding those pauses — so awkward - and leave, feeling inwardly glad.

And Grace, in Room 10, whispers low to her husband some secret - laughs softly, caressing his face with her words. Now he answers her; smiling, she nods she's alone ... for beside her lies nothing but space. He's been dead 7 years, you see. She hasn't heard. Or, at least, not a part of her anyone sees.

Bernadette, in the next bed, turns slightly away and tries vainly to sleep, block it out ... ill at ease, for she knows. She can't walk now, or see that well — slightly incontinent, too - but her mind is quite clear, and for Grace she feels pity - or anger. Or nothing.

She wishes, at times, she could no longer hear.

In the hallway sits Jim, in his chair, grinning happily (foolishly, some say). He raises an arm,

hand outstretched, tries to touch you - you shrink back with fear that is nameless, instinctive - he meant you no harm. The fingers have withered to claws, yellowed bones and blue veins showing through the translucent, frail skin (is it for reassurance you glance at your own youthful flesh?). You recover, returning his grin, greet him gently, then leave him — untouched — as he was.

You find yourself walking more quickly, because of that growing uneasiness buried within. If only those buzzers would stop — and that smell (undefined, only found in one ward) and the light that keeps flashing above that man's room.

But you know, deep inside, that it's none of those things that you fight every time you walk in here. It's something abstract, yet more real.

Can it be that they all were once young? - or did nature create separate species? That woman, right there - she has eyes like your own ...

... but you've flung

$\therefore$ the thought from you, its message too strange. With a glance

at your watch, you move into the stairwell, then past

the reception desk into the bustling street,

thinking how you must hurry.

The time goes so fast .... 